University for Business and Technology in Kosovo

UBT Knowledge Center

UBT International Conference

2017 UBT International Conference

Oct 28th, 11:00 AM - 12:30 PM

\title{
Bleeding Ulcers: Effect of low dose Aspirin - Our experience
}

\author{
Zaim Gashi \\ University for Business and Technology, zaim.gashi@ubt-uni.net \\ Elton Bahtiri \\ University of Prishtina \\ Fadil Sherifi \\ University Clinical Center of Kosovo
}

Follow this and additional works at: https://knowledgecenter.ubt-uni.net/conference

Part of the Medicine and Health Sciences Commons

\section{Recommended Citation}

Gashi, Zaim; Bahtiri, Elton; and Sherifi, Fadil, "Bleeding Ulcers: Effect of low dose Aspirin - Our experience" (2017). UBT International Conference. 292.

https://knowledgecenter.ubt-uni.net/conference/2017/all-events/292

This Event is brought to you for free and open access by the Publication and Journals at UBT Knowledge Center. It has been accepted for inclusion in UBT International Conference by an authorized administrator of UBT Knowledge Center. For more information, please contact knowledge.center@ubt-uni.net. 


\title{
BLEEDING ULCERS: Effect of Low Dose Aspirin-our Experience
}

\author{
Zaim Gashi $^{1,3}$, Elton Bahtiri ${ }^{2}$, Fadil Sherifi ${ }^{1}$ \\ ${ }^{1}$ University Clinical Center of Kosovo, Clinic for Gastroenterology with \\ Hepatology \\ ${ }^{2}$ Department of Pharmacology, Faculty of Medicine, University of Prishtina \\ ${ }^{3}$ Faculty of Nursing, UBT - Higher Education Institution, Lagjja Kalabria, 10000 p.n., \\ Prishtine, Kosovo \\ zaim.gashi@ubt-uni.net
}

\begin{abstract}
Aspirin is among the most commonly used pharmaceutical products used for the management of fever, to relieve mild to moderate pain, to reduce swelling in inflammatory conditions such as arthritis, while a low dose aspirin is used to prevent blood clots. The latter effect reduces the risk of stroke and heart attack. However, its use is associated with gastrointestinal and other complications. The aim of this study was to evaluate the influence of aspirin in bleeding ulcers. 122 patients were included in this prospective comparative study that were divided in two groups: the first group consisting of 60 patients that were treated with low dose Aspirin, and the second group consisting of 62 patients that were treated with low dose aspirin and pantoprazole (a proton pump inhibitor). All the patients had positive history for previous ulcer disease in whom bleeding ulcers were evaluated with endoscopic examinations during 12 months of treatment. The mean age of the patients with bleeding ulcers in the study was $60.4 \pm 14.3$ years, of whom $68.8 \%$ were males and $31.2 \%$ were females. In the aspirin only treated group, after 12 months of administration, bleeding ulcers were present in 11 patients $(18.3 \%)$ while in the group that were co-prescribed aspirin and pantoprazole were present only in $3(4.8 \%)$ patients. Findings from this study show that the prevalence of bleeding ulcers is significantly higher in the group treated with aspirin as monotherapy compared to the group that were co-prescribed aspirin and pantoprazole. Gastroprotection with proton pump inhibitors is essential in patients with positive history of gastrointestinal ulcers in the past that need long-term use of prophylactic low-dose aspirin.
\end{abstract}

Keywords: bleeding ulcers, aspirin, PPI

\section{Introduction}

Nonsteroidal anti-inflammatory drugs (NSAIDs) are a class of drugs that reduce pain, decrease fever, and in higher doses decrease inflammation. Side effects include an increased risk of stomach ulcers, heart attacks and renal injury $(1,2)$.

Most of the NSAIDs inhibit the cyclooxygenase-1 (COX-1) and cyclooxygenase-2 (COX-2) activity, and thereby the synthesis of prostaglandins and thromboxanes. It is assumed that inhibiting COX-2 leads to the anti-inflammatory, analgesic and antipyretic effects and that those NSAIDs also inhibiting COX-1, particularly aspirin, may cause gastrointestinal bleeding and ulcers in large doses (3). Aspirin, the only NSAID able to irreversibly inhibit COX-1, is also indicated for inhibition of platelet aggregation. This is useful for the management of thrombosis 
and prevention of adverse cardiovascular events. Aspirin inhibits platelet aggregation by inhibiting the action of thromboxane A2. An estimated 10-20\% of NSAID patients experience dyspepsia. In the 1990s high doses of prescription NSAIDs were associated with serious upper gastrointestinal adverse events, including bleeding (4). The main adverse drug reactions (ADRs) associated with NSAID use relate to direct and indirect irritation of the gastrointestinal (GI) tract. NSAIDs cause a dual assault on the GI tract: the acidic molecules directly irritate the gastric mucosa, while inhibition of COX-1 and COX-2 reduces the levels of protective prostaglandins. Inhibition of prostaglandin synthesis in the GI tract causes increased gastric acid secretion, diminishes bicarbonate secretion, diminishes mucus secretion and diminishes trophic features of the epithelial mucosa. However, their use is associated with increased risk of gastrointestinal (GI), renal and cardiovascular $(\mathrm{CV})$ effects $(5,6,7,8)$. Injury to the mucosa of the GI tract by NSAIDs is very common and ranges from minor lesions such as petechia or erosions to more serious (and also much less frequent) lesions such as ulcers, which can result in complications such as bleeding, perforation or obstruction. Patients may eventually die as a consequence of these complications (9).

Gastrointestinal lesions in NSAID or aspirin users are usually repaired rapidly through a process called 'restitution'(10). This process occurs rapidly without the need of cell division but it requires an undamaged basement membrane where healthy epithelial cells migrate. When damage does not penetrate the muscularis mucosa, the repair can be achieved within 1-3 days and involves cell proliferation and re-establishment of the glandular architecture. When an ulcer is formed (when the defect penetrates to the submucosa), repair can take from weeks to months involving re-establishment of the vasculature with new blood vessel growth. A number of growth factors including EGF and VEGF are involved in the process of ulcer repair (11).

\section{Aim of the study}

The aim of this study was to evaluate the influence of aspirin in bleeding ulcers by comparing the patients with gastrointestinal bleeding using aspirin $100 \mathrm{mg}$ who concomitantly received a proton pomp inhibitor (PPI) with those who did not receive a PPI.

Specific goals of this study were age groups, endoscopic findings and comparison of two groups of patients who had used PPI drugs with those who did not take any drugs for gastroprotection.

\section{Method and patients}

122 patients were included in this prospective comparative study that were divided in two groups: the first group consisting of 60 patients that were treated with low dose Aspirin, and the second group consisting of 62 patients that were treated with low dose aspirin and pantoprazole (a proton pump inhibitor). All the patients had positive history for previous ulcer disease in whom bleeding ulcers were evaluated with endoscopic examinations during 12 months of treatment.

\section{Material and methods}

The study was carried out at the Clinic of Gastroenterology with Hepatology at the University Clinical Center of Kosovo (UCCK) between January 2015 and December 2017. The study was retrospective, while descriptive and analytical methods were also used. There were 122 hospitalized and outpatient patients that were enrolled in the study.

Inclusion criteria included: patients over 18 years of both sexes, those who used low dose aspirin and PPI, as well as patients who used low dose Aspirin without a PPI. Clinical exams and laboratory tests and gastroscopy were performed in all study subjects. Patients were treated with modern protocols for bleeding ulcers to complete the healing process. Criteria for exclusion from 
the study were patients who have refused gastroscopy, patients who did not tolerate endoscopic examination due to cardio-respiratory pathologies as well as patients without medical reports. All gastroscopic examinations were performed with gastroscopy as well as reports of endoscopic diagnosis were analyzed. The statistical methods used were the index of structures, arithmetic mean and chi square test. For the presentation of the results, tables and graphs were used.

\section{Results}

The average age of the patients with bleeding ulcers in the study was $60.4 \pm 14.3$ years with age interval from 25 to 80 years, of whom $68.8 \%$ were males and $31.2 \%$ were females. In the aspirin only treated group, after 12 months of administration, bleeding ulcers were present in 11 patients (18.3\%). In this group, only two patients have been occasionally taking NSAIDs, during the study period. While in the group that were co-prescribed aspirin and pantoprazole, bleeding ulcers were present only in $3(4.8 \%)$ patients $(\mathrm{P}<0.01)$. In this group only one patient has been taking NSAID.

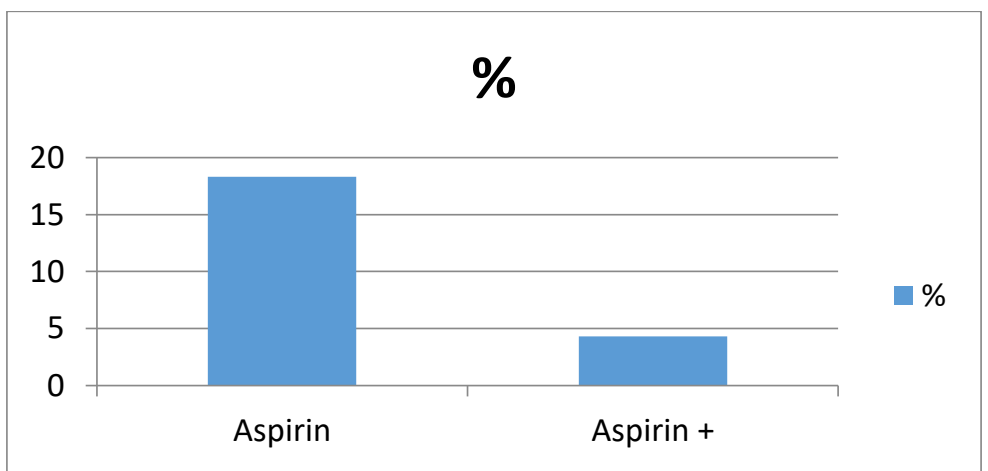

Fig. 1 Comparison of bleeding by the groups.

\section{Discussion}

Our results from this retrospective study show the need to administer PPI at the same time with the aspirin taken for cardiologic or other indications. Moreover, it was shown that bleeding ulcers in the patients who receive aspirin in love dose were significantly higher compared to patients who receive at the same time a PPI $(18.3 \%$ vs. $4.3 \%$ and $\mathrm{P}<0.01)$

Kawamura et al. evaluated 226 patients, of whom 14 (6.2\%) were endoscopically diagnosed with peptic ulcer, co-treatment with anticoagulants or proton pump inhibitors (PPIs) was significantly associated with decreased risk for peptic ulcer, The use of PPIs reduces the risk of developing gastric or duodenal ulcers in Japanese patients taking low dose aspirin without preexisting gastroduodenal ulcers (12).

Tamura and al. in their study evaluated the effect of the cessation of low dose aspirin before endoscopy and concluded that a significant association between aspirin and gastroduodenal ulcers. Moreover, patients having two or more of five factors [i.e. advanced age ( $\geq 75 \mathrm{ys})$, anticoagulants, antiplatelet drugs, NSAIDs and corticosteroids] had a significantly higher prevalence for a low dose aspirin-induced gastroduodenal ulcers. Peptic ulcer history, abdominal symptoms and the summation of risk factors increased the risk for aspirin-induced gastroduodenal ulcers. Antagonists of histamine 2 receptors (H2RAs) and PPIs were effective for the prevention of aspirin-induced gastroduodenal ulcers (13). 
Pilotto et al. in their study included 676 elderly patients who were non-steroidal antiinflammatory drugs or aspirin users and 2435 non-users who consecutively underwent upper gastrointestinal endoscopy. The use of non-steroidal anti-inflammatory drugs and/or aspirin as well as antisecretory drugs (H2RAs and PPIs) was evaluated by a structured interview. Protonpump inhibitor treatment was associated with a reduced risk of peptic ulcer in both, acute and chronic non-steroidal anti-inflammatory drugs/aspirin users. Conversely, concomitant treatment with H2RAs was associated with a significantly higher risk of peptic ulcer both in acute and chronic non-steroidal anti-inflammatory drugs/aspirin users than non-users. PPI treatment resulted in an absolute risk reduction of peptic ulcer by $36.6 \%$ in acute and $34.6 \%$ in chronic nonsteroidal anti-inflammatory drugs/aspirin users. (14)

Lazzaroni et al. reported in their long-term prevention studies, that H2ARs significantly reduce duodenal ulcer rates, but are ineffective in reducing gastric ulceration. Marked acid suppression with proton pump inhibitors (omeprazole $20-40 \mathrm{mg}$, lansoprazole $30 \mathrm{mg}$ daily) also appears to be very effective in healing gastric and duodenal ulcers in patients continuing the harmful drug as well. In long-term prevention studies, omeprazole (20 mg daily) and pantoprazole (40 $\mathrm{mg}$ daily) have also been shown to reduce the risk of gastric and duodenal ulcers and non-steroidal anti-inflammatory drug-related dyspepsia. (15)

\section{Conclusions}

Findings from this study show that the prevalence of bleeding ulcers is significantly higher in the group treated with aspirin as monotherapy compared to the group that were co-prescribed aspirin and pantoprazole.

Gastroprotection with proton pump inhibitors is essential in patients with positive history of gastrointestinal ulcers in the past that need long-term use of prophylactic low-dose aspirin.

\section{Literature}

1. Bally, M; Dendukuri, N; Rich, B; Nadeau, L; Helin-Salmivaara, A; Garbe, E; Brophy, JM (9 May 2017). "Risk of acute myocardial infarction with NSAIDs in real world use: bayesian meta-analysis of individual patient data.". BMJ (Clinical research ed.). 357 j1909.

2. Lanas, A; Chan, FK (23 February 2017). "Peptic ulcer disease.". Lancet. PMID 28242110.

3. Green GA (2001). "Understanding NSAIDs: from aspirin to COX-2". Clinical cornerstone. 3 (5): 50-60. ISSN 1098-3597.

4. Traversa G, Walker AM, Ippolito FM, Caffari B, Capurso L, Dezi A, Koch M, Maggini M, Alegiani SS, Raschetti R (January 1995). "Gastroduodenal toxicity of different nonsteroidal antiinflammatory drugs". Epidemiology (Cambridge, Mass.). 6 (1): 49-54.

5. Fitzgerald GA, Patrono C. The coxibs, selective inhibitors of cyclooxygenase-2. N. Engl. J. Med. 345, 433-442 (2001).

6. Massó González EL, Patrignani P, Tacconelli S, Rodríguez LA. Variability of risk of upper gastrointestinal bleeding among nonsteroidal anti-inflammatory drugs. Arthritis Rheum. 62, 1592-1601 (2010).

7. García Rodríguez LA, Tacconelli S, Patrignani P. Role of dose potency in the prediction of risk of myocardial infarction associated with nonsteroidal anti-inflammatory drugs in the general population. J. Am. Coll. Cardiol. 52, 1628-1636 (2008). 
8. Bueno H, Bardají A, Patrignani P, Martín-Merino E, García-Rodríguez LA. Spanish casecontrol study to assess NSAID-associated ACS risk investigators. Use of non-steroidal antiinflammatory drugs and type-specific risk of acute coronary syndrome. Am. J.

Cardiol.105, 1102-1106 (2010).

9. Wallace JL, Chin BC. Inflammatory mediators in gastrointestinal defense and injury. Proc. Soc. Exp. Biol. Med. 214(3), 192-203 (1997).

10. Silen W, Ito S. Mechanisms for rapid re-epithelialization of the gastric mucosal surface. Annu. Rev. Physiol. 47, 217-229 (1985).

11. Tarnawski A, Szabo IL, Husain SS, Soreghan B. Regeneration of gastric mucosa during ulcer healing is triggered by growth factors and signal transduction pathways. J. Physiol. Paris.95(1-6), 337-344 (2001).

12. Kawamura N, Ito Y, Sasaki M1, Iida A, Mizuno M, Ogasawara N, Funaki Y, Kasugai K Low-dose aspirin-associated upper gastric and duodenal ulcers in Japanese patients with no previous history of peptic ulcers. BMC Res Notes. 2013 Nov 12;6:455. doi: 10.1186/1756-0500-6-455.

13. Tamura I, Fujita T, Tsumura H, Morita Y, Yoshida M, Toyonaga T, Hirano S, Inokuchi H, Kutsumi H, Azuma T. Low-dose aspirin-induced gastroduodenal mucosal injury in Japanese patients with arteriosclerotic disease. Intern Med. 2010;49(23):2537-45. Epub 2010 Dec 1.

14. Pilotto A, Franceschi M, Leandro G, Paris F, Cascavilla L, Longo MG, Niro V, Andriulli A, Scarcelli C, Di Mario F. Proton-pump inhibitors reduce the risk of uncomplicated peptic ulcer in elderly either acute or chronic users of aspirin/non-steroidal antiinflammatory drugs. Aliment Pharmacol Ther. 2004 Nov 15;20(10):1091-7.

15. Lazzaroni M, Bianchi Porro G. Prophylaxis and treatment of non-steroidal antiinflammatory drug-induced upper gastrointestinal side-effects. Dig Liver Dis. 2001 Dec;33 Suppl 2:S44-58. 